\title{
Factors influencing Self-help group members for selecting livestock rearing as an income generating activity
}

\author{
AMIT SINGH AND S. RAMKUMAR
}

\begin{abstract}
A study on Self-help groups (SHGs) was carried out in Durg district of Chhattisgarh State to highlight the socio-economic status of the SHGs members, to investigate the various Income generating activities taken by the SHG members and to identify the reason for selecting livestock as a major source for income. The study shows that majority of the group opting for livestock rearing that to for goat, poultry and dairy rearing. Thus three SHGs each from goat farming, dairy farming and poultry farming IGAs were selected and all the 36 members belonging to these SHGs formed the respondents of the study. The information was collected through semi structured interview schedule, group discussion and through personal interview. In addition, the SHGs with livestock rearing as IGA in Durg were involved in-group farming rather than individual farming. The SHGs were considered as ATM (any time money) by the members to meet their daily expenses, festival expenses expenditures, which include agricultural operations. The SHGs opted for livestock enterprises mainly because they want to improve their economic status, want to get additional income, advice of the officials and availability of the grazing land.
\end{abstract}

KEY WORDS : Income generating activity (IGA), Livestock, Livelihood, Self-help group

How to CITE THIS PAPER : Singh, Amit and Ramkumar, S. (2014). Factors influencing Self-help group members for selecting livestock rearing as an income generating activity. Res. J. Animal Hus. \& Dairy Sci., 5(2) : 84-87. 